\title{
O CONFLITO SERTORIANO NO OCIDENTE HISPÂNICO: O TESTEMUNHO DOS TESOUROS MONETÁRIOS
}

POR

\author{
JOSÉ RUIVO \\ Universidade Católica Portuguesa - Pólo de Viseu
}

\begin{abstract}
RESUMEN
En este artículo se inventarían y analizan los tesoros monetarios ocultos en el occidente de Hispania durante las guerras sertorianas. Se hacen también algunas consideraciones sobre el desarrollo de este conflicto que, en la región central de Portugal, parece haber asumido un protagonismo superior al que hasta ahora se le había reconocido.
\end{abstract}

\section{SUMMARY}

This essay proposes the inventory and analysis of coin hoards deposited in the West of Spain during the Sertorian wars. Some considerations are made too about the development of this conflict, in which the Portuguese central area's significance appears to be greater than what has been thought so far.

A primeira abordagem aos tesouros da época sertoriana na Hispânia foi realizada em 1949 por F. Mateu y Llopis no apêndice ao Sertorio de A. Schulten. Aquando da publicação deste trabalho não era conhecida ainda qualquer ocultação deste período no Ocidente Peninsular; presentemente o seu número aproxima-se já da dezena, com a particularidade de estarem todos localizados na região centro-portuguesa, entre os rios Tejo e Douro (cfr. mapa) ${ }^{1}$. O facto de dispormos de novos elementos, alguns dos quais ainda inéditos, justifica uma análise mais detalhada acerca desta problemática. Começaremos, antes de mais, por apresentar um breve catálogo dos achados que julgamos susceptíveis de terem sido ocultados durante o desenrolar do conflito.

\section{A. TESOUROS ATRIBUÍVEIS AO CONFLITO SERTORIANO}

\section{Castro de Romariz, Romariz, Feira, Aveiro}

Tesouro encontrado em 1843 no interior do povoado castrejo dentro de um vaso de prata. Era com-

\footnotetext{
I Para uma visão de conjunto mais actualizada sobre os tesouros sertorianos na Hispania, cfr. Amela Valverde (1990 19-24), Blázquez (1987-1988, 123-129, fig. 5-6) e Villaronga (1993, 47-54 e 81-85, mapa 6).
}

posto por 102 denários, uma argola de ouro e um objecto de prata. Deste conjunto foram inventariados 71 unidades da República até RRC 395/1 e 1 denário ibérico de śekobiŕikes (Centeno 1976-1977, 209-219).

\section{Coiço, Oliveira do Mondego, Penacova, Coimbra}

Achado descoberto na década de 80 do nosso século, por trabalhadores, durante a plantação de um eucaliptal. Ignora-se o número total de numis- mas que dele faziam parte, mas pode admitir-se que seria superior aos vinte denários actualmente inventariados, o mais recente dos quais é o exemplar RRC 366/3c, batido na Hispânia por C. Annius Lus-

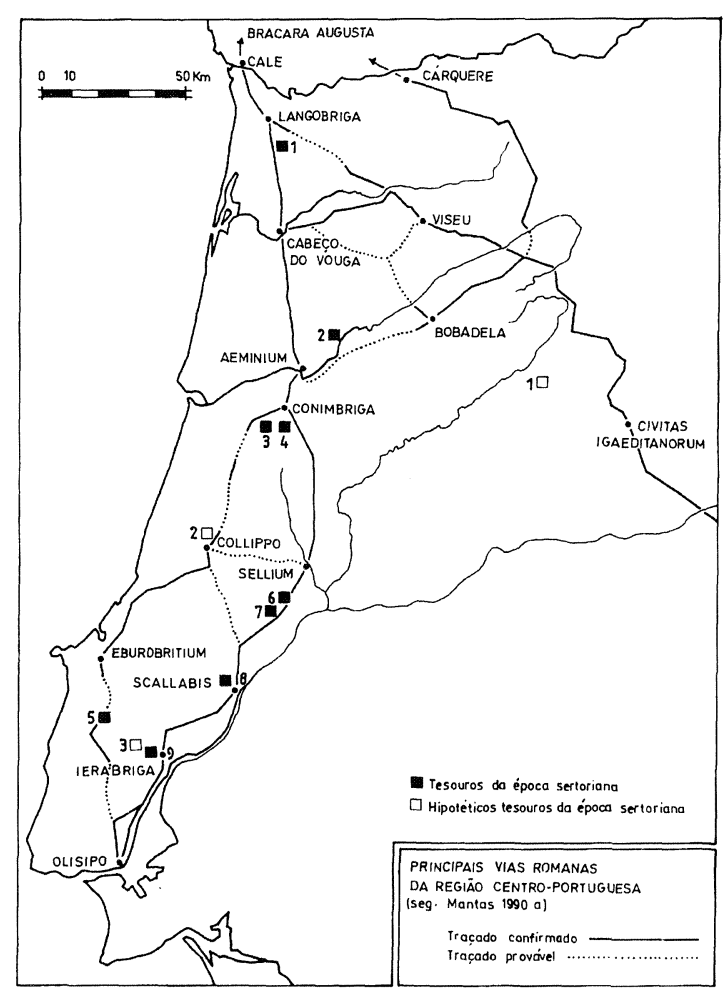


cus nos anos 82-81 a.C. Para além das moedas, recolheu-se o que parece ser parte de uma argola de prata (Fidalgo 1991, 61-62 e 66-68) ${ }^{2}$.

\section{Cabeça da Corte, Pombalinho, Soure, Coimbra}

As informações acerca deste depósito são algo confusas. Segundo Hipólito (1960-1961, 62, n ${ }^{\circ}$ 87) seria composto por uns 440 denários, descobertos por volta de 1920 dentro de um vaso de barro, a maior parte da República. Alguns anos volvidos, por informação de Hipólito, Crawford dá a indicação de que teriam sido identificadas 158 unidades até RRC $394 / 1$, esclarecendo que as unidades posteriores não deveriam fazer parte do mesmo achado ( $\mathrm{RRCH} 300$ ). Igualmente com base numa informação fornecida por Hipólito, Martín Valls $\left(1966,338, n^{\circ} 32\right)$ refere a presença de um denário de śekobiŕikes no conjunto.

\section{Vila Nova, Alvorge, Ansião, Coimbra}

Tesouro encontrado nos anos 70 na encosta entre Vila Nova e o povoado proto-histórico do Monte Figueiró, no decurso de trabalhos agrícolas. Dele conhecem-se presentemente 23 denários republicanos até RRC 394/1 e 2 denários ibéricos de bolskan (Coutinho) ${ }^{3}$.

\section{Columbeira, Columbeira, Bombarral, Leiria}

Em 1958, ao proceder-se a escavações (não arqueológicas) foi descoberto um vaso de barro nos arredores da Columbeira, contendo cerca de 980 denários republicanos. Deste conjunto estão publicados 128 numismas correspondentes a 165 unidades $^{4}$. A moeda mais recente é do tipo RRC 361/1, emitido em 82 a.C. (Hipólito 1960-1961, 75-77, n 105).

\section{Região de Torres Novas, Torres Novas, Santarém}

Leite de Vasconcellos viu na posse de um antiquário de Lisboa 4 denários provenientes de Torres

2 Agradecemos vivamente à Dra. Ana Margarida Serra Ferreira, conservadora do Museu Municipal da Figueira da Foz, as informações sobre este achado, o qual será brevemente objecto de um estudo monográfico da autoria da Dra. Isabel Pereira.

3 Devemos as informações sobre este tesouro à cortesia do $\mathrm{Rev}^{\circ} \mathrm{Pe}$. José Eduardo Reis Coutinho, que prepara presentemente a sua publicação.

4 Tal situação explica-se pelo facto de algumas das peças repetidas apenas terem sido contabilizadas uma única vez.
Novas, o mais recente dos quais correspondia a RRC 364/1, de 83-82 a.C. (Vasconcellos 1909, 59; Hipólito 1960-1961, 80, nº 113). Os numismas fariam parte de um tesouro monetário, provavelmente o da Charneca (Hildebrandt 1984, 274, n. 37; Amela Valverde 1990, 22).

\section{Charneca, Parceiros da Igreja, Torres Novas, Santarém}

Em 1908 Leite de Vasconcellos adquiriu para o Museu Etnológico (hoje Museu Nacional de Arqueologia) 5 denários romano-republicanos e um denário ibérico de bolśkan de um tesouro monetário achado na Charneca (Vasconcellos 1909, 58; Hipólito 1960-1961, 80, $\mathrm{n}^{\circ} 112$ ). A unidade mais recente é de 80 a.C. (RRC 380/1).

\section{Região de Santarém, Santarém}

Tesouro descoberto na região de Santarém pouco antes de 1989, sem que se consigam precisar o local exacto e as circunstâncias do seu achamento. Foram inventariados 192 denários, possivelmente a totalidade ou quase totalidade do tesouro. $\mathrm{O}$ exemplar mais recente reproduz o tipo RRC 394/1, de 74 a.C. (Barbosa 1995, 239-244).

\section{Casal dos Cabeços (Santana da Carnota), Carnota, Alenquer, Santarém}

Tesouro descoberto em 1979, composto por por 134 denários romano-republicanos, 1 denário de bolśkan e 1 de sekobirikes, 3 colares de prata e 10 brincos de ouro. O numisma mais recente corresponde a RRC 390/1, de 76 a.C. (Viegas e Parreira 1984, 79-91).

\section{B. TESOUROS HIPOTETICAMENTE ATRIBUÍVEIS AO CONFLITO SERTORIANO}

\section{Alcaide, Fundão, Castelo Branco}

Em 1913 foi achado um tesouro que continha denários romano-republicanos e ibéricos, dos quais se logrou identificar um de arsaos (Ramires 1953 273) e outro de bolśkan (Martín Valls 1966, 324, $\mathrm{n}^{\circ}$ 66). No decurso de uma excursão de Leite de Vasconcellos pela Beira foram-lhe oferecidos, deste 
achado, dois denários ibéricos e dois denários consulares (Vasconcellos, 1917315 e 317). É possível que estes últimos sejam os de C. Annius Luscus, actualmente no Museu Nacional de Arqueologia (Tab. 189/13-14).

\section{Região de Leiria, Leiria}

Ao descrever a visita que fez à colecção arqueológica de José Barreiros Callado, residente no Juncal (conc. de Porto de Mós, distr. de Leiria), Leite de Vasconcellos refere, a dado momento, que viu 10 denários ibéricos achados em Leiria, mas não nos indica o sítio exacto de onde provêm, nem deles faz qualquer descrição (Vasconcellos 1938, 207).

\section{Pinhal do Alvarinho, Alenquer, Santarém}

Tesouro achado nos finais do século passado, composto por cerca de 1000 denários que se encontravam dentro de um vaso de prata com a inscrição Sucnin Asedi $f$ (CIL II 62493). Deve tratar-se do mesmo achado publicado por Hipólito (1960-1961, 81-82 $\left.n^{\circ} 116\right){ }^{5}$. Hipólito Cabaço examinou três moedas que datou de 125 a.C.

Por falta de elementos não serão considerados aqui os tesouros de Monte Pindo (Boticas, Vila Real) ${ }^{6}$, Herdade do Poço do Salvado (Monsanto, Idanha-a-Nova, Castelo Branco) ${ }^{7}$ e Monsanto (Idanha-a-Nova, Castelo Branco) ${ }^{8}$.

Um tesouro com uma estrutura tipicamente sertoriana é o do Poio (Paradela de Guiães, Sabrosa, Vila Real), apesar de o exemplar mais recente ser, segundo Centeno $\left(1987,73-75, \mathrm{n}^{\circ}\right.$ 65), de 49-48 a.C. (RRC 443/1). Independentemente do facto de apenas uma parte do achado ter sido estudada, as circunstâncias que levaram à inclusão do supracitado denário, bem como o hiato de cerca de 25 anos entre essa moeda e a que lhe é imediatamente anterior (RRC 394/1a, de 74 a.C.) levam-nos, de algum modo, a partilhar das dúvidas suscitadas por Faria $(1989,92)$ e Amela Valverde $(1990,22)$.

No quadro seguinte passamos a apresentar algumas informações essenciais para a análise dos tesouros sertorianos da zona mais ocidental da Hispânia.

QUADRO 1

TESOUROS SERTORIANOS DO OCIDENTE HISPÂNICO

\begin{tabular}{|c|c|c|c|c|c|c|c|}
\hline & \multirow{2}{*}{$\begin{array}{l}\text { Total de } \\
\text { ex. }\end{array}$} & \multirow{2}{*}{$\begin{array}{l}N .^{\circ} \text { de ex. } \\
\text { estudados }\end{array}$} & \multirow{2}{*}{$\begin{array}{l}\text { Exemplar } \\
+ \text { antigo }\end{array}$} & \multirow{2}{*}{$\begin{array}{l}\text { Exemplar } \\
+ \text { recente }\end{array}$} & \multicolumn{3}{|c|}{ Centro emissor } \\
\hline & & & & & Oficial & bolśkan & sekobirikes \\
\hline Castro de Romariz & 102 & 72 & 157-156 a.C. & 74 a.C. & 71 & & 1 \\
\hline Coiço & $?$ & 20 & 155 a.C. & $82-81$ a.C. & 20 & & \\
\hline Cabeça da Corte & c. $440 ?$ & 158 & $?$ & 74 a.C. & 157 & & 1 \\
\hline Vila Nova & $?$ & 25 & 128 a.C. & 74 a.C. & 23 & 2 & \\
\hline Columbeira & c. 980 & 165 & 157-156 a.C. & 82 a.C. & 165 & & \\
\hline Charneca & $?$ & 6 & 119 a.C. & 80 a.C. & 5 & 1 & \\
\hline Torres Novas & $?$ & 4 & 112-111 a.C. & $83-82$ a.C. & 4 & & \\
\hline Região de Santarém & $192 ?$ & 192 & 225-214 a.C. & 74 a.C. & 192 & & \\
\hline Santana da Carnota & 136 & 136 & 206-195 a.C. & 76 a.C. & 134 & 1 & 1 \\
\hline
\end{tabular}

Deste conjunto de tesouros, os de Santarém e Santana da Carnota estarão, em princípio, completos. $\mathrm{O}$ tesouro do castro de Romariz está bastante bem repre-

5 Embora Hipólito, fundamentando-se numa informação de Hipólito Cabaço, refira que o tesouro estava repartido por duas taças de prata, preferimos seguir Hübner que afirma tratar-se apenas de uma, considerando que o estudioso alemão recebe a notícia de Estácio da Veiga em época muito próxima do achado. Segundo Faria (1990-1991, 83 e 88), os antropónimos gravados na inscrição da taça podem representar a transcrição para o alfabeto latino dos nomes ibéricos *suk(u)nin e *aseti, embora Gorrochategui Churruca (1984, 150) defenda uma origem aquitana para este último nome (Asedus). Tudo parece apontar no sentido de a formação do tesouro ter ocorrido em local muito distante daquele onde viria a ser abandonado. sentado, o mesmo podendo acontecer com os achados de Vila Nova e do Coiço. Do tesouro da Columbeira temos uma amostra razoável, cifrada em cerca de

6 Centeno $\left(1987,66, \mathrm{n}^{\circ} 55\right.$ e 193-194), tendo em atenção o considerável desgaste das moedas mais recentes sugere, quanto a nós bem, uma data de ocultação bastante tardia, enquanto Blázquez (1987-1988, 126, n 64) e Villaronga $\left(1993,54, n^{\circ} 120\right)$, optam pela inclusão do achado no lote dos tesouros sertorianos.

7 Tesouro composto por, pelo menos, 73 denários achados dentro de um vaso de prata (Vasconcellos 1920, 106; Hipólito 1960-1961, 70-71, n 97; Faria 1989, 93).

8 RRCH 229; Faria 1989, 93; Villaronga 1993, 53, $\mathrm{n}^{\circ}$ 117. Segundo Pires (1898, 79-80), tratar-se-ia de um conjunto de 4 moedas com diversas proveniências, uma vez que teriam sido achadas no castelo de Monsanto e arredores. 
$17 \%$ da globalidade do depósito. Para os restantes a informação disponível revela-se insuficiente.

O tesouro de Santana da Carnota fecha com um exemplar de 76 a.C. (RRC 390/1), enquanto os de Vila Nova, Santarém e, possivelmente, o de Cabeça da Corte terminam com unidades de 74 a.C. (RRC 394/ 1), o mesmo sucedendo com o do castro de Romariz (RRC 395/1). A ocultação destes tesouros parece situar-se, portanto, na fase final do conflito sertoriano.

É de realçar o facto de não dispormos, com toda a segurança, de nenhum achado relacionável com as etapas iniciais da disputa, embora não seja despicienda a possibilidade de a ocultação os tesouros da Columbeira e do Coiço se ter processado logo nos inícios da contenda.

Na opinião de F. García Morá (1991, 101-102), na sua ofensiva inicial de 79 a.C., o governador da Ulterior, Q. Cecílio Metelo, teria atacado os territórios lusitanos a Norte do Tejo, onde viria a ter lugar o célebre episódio do cerco de Langobriga narrado por Plutarco (Sert., 13, 7-12). Verificam-se, a propósito desta povoação, grandes divergências entre os investigadores quanto ao seu nome e localização. Schulten $(1926,71)$ opta pela grafia Lacobriga e situa-a em Lagos, no Algarve, opinião que também já foi partilhada por Alarcão (1988a, 24), embora em trabalho posterior este autor se mostre mais cauteloso (Alarcão 1990a, 349). Tovar (1976, 257-258), por seu turno, adopta a grafia Langobriga posicionando-a a Norte de Aveiro, tal como Spann (1981, 233-234), que distingue a Langobriga do texto de Plutarco da Lacobriga mencionada em Pompónio Mela e Ptolemeu, essa sim, localizada na costa algarvia.

Independentemente desta problemática, parecenos crível que as tropas de Metelo tenham atacado as populações lusitanas que viviam a Norte do Tejo. $\mathrm{O}$ estabelecimento de um acampamento em Caeciliana, algures nas imediações de Setúbal (Tovar 1976, 216; Alarcão 1988b, 56), poderia ser um indicador desta ofensiva militar. É possível que os acampamentos de Chões de Alpompé (Santarém) ${ }^{9} \mathrm{e}$ de Antanhol (Coimbra) tenham servido como bases operacionais durante esta fase da guerra.

9 As opiniões sobre a cronologia do abandono deste acampamento são algo divergentes. Diogo (1993, 219) sugere que a sua ocupação terá cessado na época de César, enquanto Fabião $(1989,98)$ a situa nos inícios do séc. I a.C. Temos boas razões para crer que a desactivação do acampamento teve lugar nos primeiros anos do conflito que opôs Metelo a Sertório. Quando a redacção deste artigo já estava em fase terminal chegou-nos às mãos um conjunto de cerca de 150 numismas provenientes deste local, entre os quais se encontra um pequeno tesouro que poderá ter sido ocultado aproximadamente por esta época. Dos restantes exemplares o mais recente é o denário RRC 374/2, cunhado por Metelo no Norte de Itália em 81 a.C.
Uma vez superada a investida de Metelo, Sertório irá contra-atacar com êxito, alargando a sua influência aos territórios a Sul do Tejo e obrigando o seu adversário a recuar para o coração da Ulterior e a optar por uma postura mais defensiva, atitude bem retratada no abandono do acampamento de Cáceresel-Viejo (Castra Caecilia ?) provavelmente após um ataque de Sertório (Ulbert 1984, 207-211).

Daqui em diante, as fontes clássicas mostram-se omissas relativamente a acções que possam ter-se desenrolado nesta área, exceptuando uma breve notícia relativa a uma expedição de Perperna a Cale (Salústio, Hist., III, 43 = Sérvio, Ad Aen., VII, 728), realizada na Primavera de 75 a.C. se dermos crédito à cronologia recentemente proposta por Konrad (1995, 157-187) ou em fins de 74 a.C. se seguirmos a cronologia tradicional.

Partindo do princípio que a Cale de Salústio é identificável com a cidade homónima que existiu na foz do Douro, e a identificação não é pacífica ${ }^{10}$, urge perguntar qual o móbil do lugar-tenente de Sertório. A resposta que nos ocorre é que o partido sertoriano já não controlava em absoluto os territórios mais ocidentais da Hispânia e que o início da derrocada do poder do general estaria a provocar algum esmorecimento na fidelidade das populações indígenas ${ }^{11}$.

Esta movimentação militar destinar-se-ia a pressionar as populações da faixa litoral a Norte do Tejo no sentido de se manterem fiéis ao partido sertoriano, podendo a presença destes tesouros indiciar que terão sido desencadeadas acções militares contra vários povoados da região.

Tal conjuntura poderá ter motivado a deposição dos tesouros monetários de Santana da Carnota, Santarém, Vila Nova, Cabeça da Corte, Castro de Romariz e, num plano meramente conjectural, do achado do Poio, a que atrás se fez referência.

Contudo, o peso desta argumentação diminui consideravelmente se tivermos em consideração os seguintes factores:

1. As propostas de Hersh e Walker (1984, 103 134) para a cronologia das emissões de denários romanos que fecham a maior parte dos nossos te-

10 Contra esta identificação pronunciou-se Machado (s/d 17-42). Também Fabião manifesta dúvidas quanto à possibilidade de se relacionar este oppidum com o povoado de Castelo de Gaia ou com o castro do Morro da Sé do Porto (Fabião 1992, 221-222).

1 Este facto é confirmado pelas passagens de Plutarco (Sert., 25, 4-5) e de Apiano (Iber. 1, 112), que relatam o início da defecção dos aliados ibéricos e romanos de Sertório. Do mesmo ponto de vista partilha Alarcão (1990a, 349). Opinião diversa é manifestada por García Morá (1991, 325), ao pretender que o objectivo de Perperna seria aliciar as populações galaicas meridionais para a sua causa após a perda da Celtibéria e do Vale do Ebro. 
souros. Segundo estes investigadores, a emissão RRC 394/1 de C. Postumius que fecha o tesouro de Santarém e, provavelmente, os de Cabeça da Corte e Vila Nova, seria datável de 73 a.C. e não de 74 a.C. como sugere Crawford. Também o denário RRC 390/1-2, de L. Lucretius Trio, que corresponde ao exemplar mais recente do depósito de Santana da Carnota avançaria de 76 para 74 a.C., enquanto a moeda mais recente do tesouro do castro de Romariz (RRC 395/1, de L. Cossutius Sabula) passaria de 74 para 72 a.C.

2. A nova cronologia recentemente estabelecida por Konrad para o conflito sertoriano. Este autor situa a expedição de Perperna a Cale na Primavera de 75 a.C. e o assassinato de Sertório na segunda metade de 73 a.C.

Vejamos agora como se articulam as datações das emissões de denários (sugeridas por Crawford, 1974 e por Hersh e Walker) com as cronologias (tradicional e de Konrad) propostas para a campanha de Perperna:

1. Cronologia tradicional (74 a.C.):

a) Crawford: os depósitos de Santana da Carnota, Santarém, Vila Nova, Cabeça da Corte e do Castro de Romariz poderão estar associados à expedição de Perperna;

b) Hersh e Walker: apenas o tesouro de Santana da Carnota poderia ser contemporâneo da expedição, os restantes seriam posteriores.

2. Cronologia de Konrad (Primavera de 75 a.C.):

a) Crawford: só o tesouro de Santana da Carnota poderia ser interpretado à luz da campanha de Perperna;

b) Hersh e Walker: todos os achados citados seriam posteriores àquele acontecimento.

Os elementos que temos à nossa disposição são ainda bastante fragmentários e carecem da confirmação da arqueologia. Todavia, parece-nos que a passagem de um exército provocaria um clima de instabilidade entre as populações locais, de que os tesouros monetários constituiriam um reflexo evidente. Não deixa de se afigurar como uma grande coincidência o facto de vários depósitos se poderem enquadrar tão bem nesta movimentação. Não sendo de excluir a possibilidade de algumas destas ocultações terem sido motivadas pela ocupação romana da região após a morte de Sertório, parece-nos que há boas hipóteses de, contrariando quer as cronologias de Hersh e Walker ${ }^{12}$, quer as de Konrad, admitirmos

12 As cronologias propostas por estes autores tem merecido algumas reservas. Recentemente García-Bellido teve o ensejo de contestar a datação sugerida para a emissão do denário RRC 397, que fecha o tesouro de Palenzuela, pois a sua íntima conexão com a deslocação do lugar-tenente de Sertório a Cale.

Porém, a formação de alguns destes tesouros poderá ter ocorrido em áreas bastante distantes dos locais de achado (Faria 1989, 93 e, sobretudo, 19911992, 93-94). Muitos deles poderão representar não as posses de um autóctone, mas o produto de saques efectuados em regiões longínquas após uma refrega ou a tomada de uma povoação ou até constituirem parte do estipêndio ${ }^{13}$. Outras vezes poderá ser o próprio recrutamento militar a justificar a ocultação: antes de partir, o futuro soldado põe a salvo esta parte do seu património ${ }^{14}$. A análise desta hipótese levar-nos-ia longe, nomeadamente à questão do recrutamento de auxiliares indígenas pelos romanos ${ }^{15}$, bem como à das formas de pagamento utilizadas.

Se, na maior parte dos casos, ignoramos o local preciso onde foram descobertos estes tesouros, não deixa de ser interessante constatar que a maioria dos depósitos sertorianos foi exumada na proximidade de povoados indígenas ${ }^{16}$. O tesouro do Castro de Romariz foi recolhido no interior do povoado (Centeno 1976-1977, 210). O tesouro de Vila Nova foi encontrado a cerca de 500 metros do Monte Figueiró ${ }^{17}$; o da Columbeira numa região onde se eleva o castro homónimo, com uma importantíssima ocupação da Pré-história recente e posterior (Schubart et alii 1969, 12-36; Coffyn 1985, 214); o de Santana da Carnota numa área onde são conhecidos vários povoados da Idade do Ferro, como os castros das Curvaceiras ${ }^{18}$ e da Ota $^{19}$ ou a própria Ierabriga ${ }^{20}$.

esta unidade avançaria de 74 para 71 a.C., situando o entesouramento num período posterior ao conflito sertoriano, o que, segundo a autora, seria pouco congruente com o contexto da Celtibéria (García-Bellido 1994, 248, n. 10).

13 Durante as guerras sertorianas o soldo seria pago preferencialmente em AR (Zehnacker 1983, 111).

14 Esta possibilidade é sugerida por Crawford (1969a, 79 e 1985 193). A importância do fenómeno do recrutamento na deposição de vários tesouros monetários é igualmente realçada por Duncan-Jones (1994, 83-84).

15 Sobre o recrutamento dos indígenas pelos romanos, $\mathrm{cfr}$. García y Bellido (1963, 213-226) e Roldán Hervás (1993, 78-88).

16 Para Alarcão (1990b, 483) muitos dos tesouros achados em castros seriam propriedade colectiva dos seus habitantes.

17 ocupação pré-romana deste povoado não oferece dúvidas (Coutinho 1994, 113-114 e 1995, 194-195).

18 Neste povoado foi encontrada nos inícios do século uma moeda de bronze hispano-cartaginesa do tipo $\mathrm{CNH} 41$ (Corrêa 1928, 204 e Ruivo 1995, $55 \mathrm{n}^{\circ}$ 68). Agradecemos ao Sr. Prof. Doutor Rui Centeno a informação que nos permitiu a classificação exacta da moeda.

19 Também para este local temos notícia do achado de denários republicanos (Barbosa 1956,117) e de um quarto de shekel hispano-cartaginês do tipo CNH 15 (Ruivo 1995, 56 n $^{\circ} 69$ ).

20 Esta povoação situar-se-ia talvez entre Paredes e Sete Pedras, nos arredores de Alenquer (Mantas 1990b, 162, n. 57). 
A este grupo poderemos também acrescentar, se bem que a título meramente hipotético, os achados do Pinhal do Alvarinho, da região de Leiria e do Alcaide $^{21}$. Dos três, este último é o que nos parece com maiores possibilidades de ser efectivamente sertoriano, apesar de existirem boas razões para supormos que todos eles terão sido ocultados entre finais do séc. II - inícios do I a.C. e o término das guerras sertorianas ${ }^{22}$.

Outro aspecto que julgamos pertinente discutir aqui é o seguinte: analisando a distribuição espacial dos tesouros sertorianos conclui-se que estes evidenciam uma espantosa tendência para se alinharem ao longo daqueles que virão a ser, futuramente, os eixos viários capitais da região centro-portuguesa (Alarcão 1988b, 52-53, fig. 24; Mantas 1990a, 219-239). Como se pode observar no mapa em anexo, a maior concentração de tesouros está disposta ao longo do eixo principal da futura via Olisipo-Bracara Augusta, ao mesmo tempo que outra concentração menos importante se localiza naquele que virá a ser o seu ramal secundário. Tudo aponta, portanto, no sentido de as vias imperiais se terem sobreposto aos caminhos que, nos finais na Idade do Ferro - e provavelmente já desde o Bronze Final ${ }^{23}$ —, asseguravam a ligação entre os povoações mais importantes, facilitando as transacções dos produtos, mas também as deslocações dos contingentes militares ${ }^{24}$.

Apenas o tesouro do Coiço parece sair da órbita da primacialidade dos eixos viários, mas a sua localização, próxima ao Mondego, realça a importância deste curso de água na penetração romana na Lusitânia.

Analisando agora a composição dos tesouros de Romariz, Coiço, Vila Nova, Columbeira, Santarém e Santana da Carnota segundo a periodização estabelecida por Crawford (1974), notamos que o mais completo é o de Santarém (cfr. Quadro 2), onde a moeda mais antiga é uma didracma de 225-214 a.C. e onde a peça mais recente datará de 74 a.C. Este é, juntamente com o tesouro de Empordà (Vilaret i Monfort 1976, 47-60) ${ }^{25}$, um dos únicos tesouros sertorianos onde o período Ia está representado, embora se deva colocar a hipótese de a presença de unidades tão antigas ser o reflexo de uma circulação residual, o mesmo se aplicando às do período Ib. Poder-se-á todavia admitir que, num caso ou noutro, se trate de normal entesouramento.

QUADRO 2

ESTRUTURA DE VÁRIOS TESOUROS SERTORIANOS SEGUNDO A PERIODIZAÇÃO DE CRAWFORD (\%)

\begin{tabular}{|c|c|c|c|c|c|c|c|c|}
\hline & Romariz & Coiço & Vila Nova & Columbeira & Santarém & S. Carnota & Empordá & Nerpio \\
\hline $\begin{array}{l}\text { Ante } 211 \text { a.C. } \\
\text { Ia }(211-207 \text { a.C. }\end{array}$ & & & & & $\begin{array}{l}0.57 \\
1.14\end{array}$ & & 1.95 & \\
\hline Ib (c. 206-c. 144 a.C.) & 8.57 & 5.00 & & 8.66 & 6.25 & 5.22 & 5.84 & 2.95 \\
\hline Ic (c. 143 -c. 125 a.C.) & 4.28 & 10.00 & 4.35 & 22.83 & 15.91 & 9.70 & 10.62 & 10.45 \\
\hline Id (c. 124-c. 92 a.C.) & 38.57 & 50.00 & 13.04 & 49.61 & 38.06 & 35.82 & 29.82 & 20.86 \\
\hline Ie (91-79 a.C.) & 38.57 & 35.00 & 69.57 & 18.90 & 31.82 & 48.51 & 45.22 & 62.58 \\
\hline If (78-49 a.C.) & 10.00 & & 13.04 & & 6.25 & 0.75 & 6.55 & 2.95 \\
\hline
\end{tabular}

Ao contrário do tesouro de Santarém, o de Vila Nova parece ter sido reunido num curtíssimo espaço de tempo. Ao exemplar mais antigo (128 a.C.) seguem-se um de 111-110 a.C. e outro de 101 a.C. A maioria esmagadora dos numismas concentra-se no período Ie, em paralelo com o tesouro de Nerpio,

21 A possibilidade de este depósito estar associado ao conflito sertoriano fora já sugerida por Faria $(1989,93)$.

22 A cronologia da maior parte dos tesouros em cuja composição entram os denários ibéricos não ultrapassa o final das guerras sertorianas. Conhecem-se, no entanto, vários achados com unidades ibéricas ocultados em épocas posteriores, entre os quais os de S. Mamede de Ribatua (Centeno 1987, 81-82, no 76), Castro de Arrabalde (Sánchez de Arza 1984, 51-64) e Villar del Álamo, também conhecido por tesouro de Albacete (Villaronga 1971-1972, 305-320).
Albacete (Vidal Bardán 1984, 41-50). Neste caso concreto, as emissões dos períodos anteriores têm também um valor residual. Contudo estas considerações encontram-se de algum modo limitadas pela reduzida massa monetária que compõe este depósito. No tesouro do Coiço, o período mais bem repre-

23 Mantas (1990a, 220), realça que a facilidade de deslocação dos bandos lusitanos e dos exércitos republicanos se deveria à utilização de velhos caminhos indígenas.

24 Embora na posse de dados muito parcelares para os tesouros sertorianos da Lusitânia, Amela Valverde (1990, 22) salienta que todos aqueles por ele apresentados se encontram junto a vias de comunicação, o mesmo ocorrendo com os achados da Estremadura espanhola, situados junto à via de la Plata. 
sentado é o Id, enquanto as emissões do período If estão ausentes, o mesmo se verificando com o da Columbeira, mas a análise deste último tesouro é afectada pelo facto de o material disponível representar apenas cerca de um sexto do total.

O tesouro de Santana da Carnota tem, ao nível da estrutura, algumas semelhanças com o tesouro de Empordà -embora as suas unidades mais antigas sejam posteriores- e com o tesouro de Nerpio, mas o seu período If está fracamente representado. Convém contudo não esquecer que a moeda que fecha este depósito tem uma cronologia anterior à dos tesouros espanhóis.

Em termos gerais, podemos dizer que todos estes tesouros se caracterizam por uma elevada percentagem de numerário nos períodos mais recentes - exceptuando o último-, percentagem essa que vai decrescendo progressivamente à medida que recuamos no tempo. Esse valor também é muito reduzido no período que fecha cada tesouro, pelo simples facto de a moeda recém-cunhada demorar algum tempo a entrar nos circuitos monetários. Durante o conflito sertoriano, a necessidade de subsidiar as operações militares deve ter acelerado consideravelmente o processo, apesar de termos notícia das dificuldades por que passaram os generais beligerantes para se abastecerem de numerário. Em 76 a.C. Metelo só recebeu moeda enviada da Gália Narbonense e, em 75 ou 74 a.C., Pompeio envia uma carta ao Senado a dar conta das dificuldades de manutenção do exército (Salústio, Hist., II, 98). O problema do aprovisionamento só terá sido solucionado, na opinião de M. Crawford, com a volumosa emissão de C. Postumius (RRC 394) que fecharia vários tesouros hispânicos desta época, entre os quais os de Vila Nova, Santarém, Cabeça da Corte e Nerpio (Crawford 1969a, 84 e 1985, 213).

Nos tesouros que temos vindo analisar, o aprovisionamento de AR começa a ganhar alguma expressão durante o período $\mathrm{Ic}^{26}$ para, na maior parte dos casos, atingir o seu ponto máximo no período Ie. Este é, com frequência, o período melhor representado (alternando por vezes com o período Id), já que é durante este espaço de tempo que o volume das

25 Têm-se levantado agumas dúvidas acerca da cronologia deste depósito (cfr. Vilaret i Monfort 1976, 47 e Amela Valverde 1990, 20). Nós, atendendo à representatividade do numerário que o compõe, entendemos utilizá-lo para efeitos comparativos.

${ }^{26}$ A idêntica conclusão chega Amela Valverde (1990, 2425), que situa este crescimento na década de 139-130 a.C. correspondendo ao primeiro grande aumento do volume das emissões em Roma. emissões em Roma atinge os níveis mais elevados (Crawford 1969b, 702-705) ${ }^{27}$.

Como vimos no Quadro 1, o tesouro de Santarém e, a título hipotético, os da Columbeira e do Coiço são compostos exclusivamente por numerário emitido em Roma ou pelos generais romanos em campanha ${ }^{28}$. Os restantes vêem entrar na sua composição as emissões de prata ibérica, embora em proporções que podem ser consideradas irrelevantes. Não deixa de ser curioso constatar que, numa região sob o controlo do partido sertoriano, as emissões ibéricas tenham conhecido um papel tão marginal $^{29}$. As parcas unidades que surgem nos entesouramentos do Oeste hispânico associadas a denários romanos foram produzidas em alguns dos centros emissores mais operosos na Hispânia durante esta época: bolśkan ${ }^{30}$, sekobirikes ${ }^{31}$ e arsaos, sobretudo os dois primeiros.

Esta fraca dimensão das emissões ibéricas de AR nos tesouros sertorianos do Ocidente hispânico é confirmada pela análise do material proveniente dos achados isolados e das escavações ${ }^{32}$ : há apenas a registar o achado de dois denários de bolśkan recolhidos, respectivamente, em Lisboa (Vasconcellos 1900, 286) e Idanha-a-Velha, Castelo Branco (Mateu y Llopis 1949, 218), assim como de um denário de śekobirikes descoberto nas imediações de Perula, Coimbra (Martín Valls 1966, 338, nº 31).

Como justificação para este fenómeno poder-seá argumentar que a região centro-portuguesa está geograficamente muito afastada dos principais centros emissores ibéricos, mas talvez seja mais realista admitir que, nesta época, as populações ainda não

27 A fiabilidade dos cálculos efectuados por Crawford é muito justamente colocada em questão por vários autores, como Mattingly (1977, 199-215 e 1982, 27-29), Lo Cascio (1982, 75-97) e Burnett (1987, 179).

${ }_{28}$ Caso dos famosos denários de C. Annius Luscus (RRC 366/3-4) batidos na Hispânia entre 82 e 81 a.C.

29 Foram estas emissões que asseguraram, em boa medida, o esforço de guerra sertoriano (Gaggero 1976, 55-75; Crawford 1985, 210; Villaronga 1995, 11-14). Porém, convirá não esquecer que Sertório terá trazido de Itália grandes quantidades de moeda oficial, de que voltou a ser abastecido com a chegada de Perperna (Plutarco, Sert., 15,1).

30 Entre os centros emissores ibéricos desta fase, bolśkan foi aquele cujas emissões tiveram maior volume e conheceram maior difusão (Martín Valls 1966, 233-235 e 309; Domínguez Arranz 1979, 86-99 e 351, Mapa 6).

31 Sobre a circulação da moeda de śekobiŕikes, cfr. Martín Valls (1966, 337-338 e 364, Mapa XXI), García-Bellido (1974, 392-393 e 1994, 250, fig. 8) e Barahona Ramos (1994, 597-621).

32 Centeno (1987, 202-203, n. 92), a circulação da prata ibérica deve ter sido reduzida no Ocidente peninsular. Para o Noroeste este autor recenseou apenas 19 denários ibéricos provenientes de achados avulso, 16 dos quais oriundos do conventus Asturum. 
faziam uso corrente da moeda, estando o seu usufruto restringido a certos grupos de indivíduos, como os militares e alguns comerciantes, ou a povoações ligadas a actividades mercantis. Aliás, a ausência de moeda republicana em contextos que possam ser associados a esta época ${ }^{33}$, parece demonstrar que a moeda ainda não era utilizada pelas populações nas trocas quotidianas. Os tesouros sertorianos documentam a primeira chegada massiva de moeda ao Ocidente hispânico pelo que, só a partir desta época, se poderão ter dado os primeiros passos no sentido da sua progressiva generalização.

A relativa abundância de tesouros da época sertoriana nesta franja ocidental da Península Ibérica, parece mostrar que esta região desempenhou um papel bastante importante, e até há pouco tempo insuspeitado $^{34}$, na etapa que marca o epílogo da guerra civil entre populares e aristocratas.

\section{BIBLIOGRAFIA}

Alarcão, J., 1988a: O domínio romano em Portugal, Mem Martins.

AlarCão, J., 1988b: Roman Portugal, 2 vols., Warminster.

Alarcão, J., 1990a: A conquista do território, in Serrão, J. e Marques, A. H. O (dir.), Nova História de Portugal, Lisboa, pp. 345-351.

Alarcão, J., 1990b: A produção e a circulação dos produtos, in Serrão, J. e Marques, A. H. O (dir.), Nova História de Portugal, Lisboa, pp. 409-441.

33 Tal facto pode explicar-se, em primeiro lugar, pela ausência de trabalhos arqueológicos de grandes dimensões em sítios com ocupação republicana. Boa parte das 38 moedas recuperadas nas escavações de Conimbriga foram encontradas em contextos de demolição claudianos, nas camadas de enchimento do centro monumental flaviano e na remodelação das termas trajânicas (Hiernard et alii 1974, pp. 6-8, 195 e 198-201), não permitindo extrair quaisquer ilações. As excepções no Oeste hispânico são, por enquanto, o acampamento dos Chões de Alpompé onde, para além dos dois exemplares já publicados (Diogo e Faria 1985, 120-122), se recolheu recentemente um importante conjunto de denários e bronzes romano-republicanos e hispânicos (cfr. supra n. 9), e o acampamento da Lomba do Canho (Arganil). Todavia, a ocupação deste local, certamente justificada pela necessidade de controlar uma zona rica em minério (estanho e ouro de aluvião), não deve ter-se iniciado antes da década de 60 (Nunes et alii 1989, 412-413). Por outro lado, urge perguntar em que medida é que as 30 moedas $(7 \mathrm{AR}+23 \mathrm{AE})$ aí recolhidas (Faria 1984-1985, 37-42) podem ser entendidas como reflexo de uma normal circulação da moeda? Parece-nos que a resposta terá que ser negativa, uma vez que a sua utilização se restringiria, em princípio, à guarnição.

${ }^{34} \mathrm{O}$ ponto actual da questão foi excelentemente traçado por Fabião (1992, 221-223).
Amela Valverde, L., 1990: La circulación monetaria romano-republicana durante la guerra sertoriana según las ocultaciones de la época (82-72 a.C.), GN, 97-98, pp. 19-30.

Barahona Ramos, J. J., 1994: La ceca de Sekobirikes, III Congreso Peninsular de Historia Antigua - Preactas (Vitoria-Gasteiz, Julho de 1994), pp. 597-621.

Barbosa, E., 1956: O castro da Ota (Alenquer), $A P$, n.s., 3, pp. 117-124.

Barbosa, M. B., 1995: Um tesouro sertoriano da região de Santarém, I Encuentro Peninsular de $\mathrm{Nu}$ mismática Antigua (Madrid, 7-10 Novembro 1994), Anejos de AEspA, XIV, Madrid, pp. 239244.

BlÁzQuez, C., 1987-1988: Tesorillos de moneda republicana en la península ibérica. Addenda a Roman Republican Coin Hoards, ActNum, 1718, pp. 105-142.

BurnEtT, A., 1987: The changing face of Republican numismatics, JRS, LXXVII, 1987, pp. 177-183.

Centeno, R. M. S., 1976-1977: O tesouro monetário de Romariz (Portugal), Sautuola, II, pp. 209-219.

Centeno, R. M. S., 1987: Circulação monetária no Noroeste de Hispânia até 192, anexos Nummus, $\mathrm{n}^{\circ} 1$, Porto.

$\mathrm{CNH}=$ VILLARONGA 1994

Coffyn, A., 1985: Le Bronze Final Atlantique dans la Péninsule Ibérique, Paris.

Correa, A. A. M., 1928: A Lusitânia pré-romana, in Peres, D. (dir.), História de Portugal, t. I, Barcelos.

Coutinho, J. E. R., 1994: Monte Figueró, in VV. AA., Idade do Ferro, Catálogo da exposição realizada no Museu Municipal Dr. Santos Rocha, Figueira da Foz, pp. 113-114.

Coutinho, J. E. R., 1995: Moedas hispano-romanas do Monte Figueiró, Conimbriga, XXXIV, pp. 191-204.

Coutinho, J. E. R.: Entesouramentos de denários republicanos em Alvorge (a publicar).

Crawford, M. H., 1969a: The financial organization of Republican Spain, $N C$, $7^{\text {a }}$ s., IX, pp. 79-93.

Crawford, M. H., 1969b: Roman Republican Coin Hoards, Londres.

Crawford, M. H., 1974: Roman Republican Coinage, Cambridge, 2 vols.

Crawford, M. H., 1985: Coinage and money under the Roman Republic. Italy and the Mediterranean economy, Londres.

Diogo, A. M. D., 1993: Ânforas pré-romanas dos Chões de Alpompé (Santarém), Estudos Orientais, IV, pp. 215-227.

Diogo, A. D. e FARiA, A. M., 1985: Moedas roma- 
nas provenientes dos Chões de Alpompé (Santarém), Arqueologia, 11, pp. 120-122.

Domínguez ARranz, A., 1979: Las cecas ibéricas del valle del Ebro, Saragoça.

Duncan-Jones, R., 1994: Money and government in the Roman Empire, Cambridge.

FABIÃo, C., 1989: Sobre as ânforas do acampamento romano da Lomba do Canho (Arganil), Lisboa.

FABIÃo, C., 1992: O passado proto-histórico e romano, in Mattoso, J. (dir.), História de Portugal. Vol. I-Antes de Portugal, Lisboa, pp. 76-299.

FARIA, A. J., 1984-1985: As moedas do acampamento romano da Lomba do Canho (Arganil), Nummus, $2^{\mathrm{a}}$ s., VII-VIII, pp. 37-42.

FARIA, A. M., 1987: Guerras e conflitos no Vale do Tejo na Antiguidade: o testemunho dos tesouros monetários, in VV. AA., Arqueologia do Vale do Tejo, Lisboa, pp. 60-61.

FArIA, A. M., 1989: Sobre a moeda no Noroeste da Hispânia. Alguns comentários ao recente livro do Doutor Rui Centeno, Arqueologia, 20, pp. 9096.

FARIA, A. M., 1990-1991: Antropónimos em inscrições hispânicas meridionais, Portugália, n. s., XI-XII, pp. 72-88.

FARIA, A. M., 1991-1992: Três tesouros monetários da época republicana, Nummus, $2^{\mathrm{a}}$ s., XIV-XV, pp. 79-94.

FIDAlgo, J. O., 1991: Levantamento arqueológico do concelho de Penacova (trabalho escolar), Coimbra, Instituto de Arqueologia.

GAGgero, G., 1976: Aspetti monetari della rivolta Sertoriana in Spagna, RIN, vol. XXIII, $6^{\mathrm{a}} \mathrm{s}$, LXXVII, pp. 55-75.

García Mora, F., 1991: Un episodio de la Hispania republicana: la guerra de Sertorio. Planteamientos iniciales, Granada.

García y Bellido, A., 1963: Los auxiliares hispanos en los ejércitos romanos de ocupación (200 al 30 antes de J.C.), Emerita, XXXI (2), pp. 213-226.

García-Bellido, M. P., 1974: "Tesorillo" salmantino de denarios ibéricos, Zephyrus, XXV, pp. 379-395.

GarcíA-Bellido, M. P., 1994: Sobre la localización de Segobrix y las monedas del yacimiento de Clunia, AEspA, 67, pp. 245-259.

Gorrochategui Churruca, J., 1984: Estudio sobre la onomástica indígena de Aquitania, Bilbao.

Hersch, C. e Walker, A., 1984: The Mesagne hoard, ANSMN, 29, pp. 103-134.

Hiernard, J. et alii, 1974: Fouilles de Conimbriga. III-Les monnaies, Paris.

Hildebrandt, H. J., 1984: Die Münzen aus Cáceres el Viejo, in Ulbert, G., Cáceres el Viejo. Ein spätrepublikanisches Legionslager in SpanischExtremadura, Madrider Beiträge, Band 11, Mainz am Rhein, pp. 257-297.

HiPólito, M. C., 1960-1961: Dos tesouros de moedas romanas em Portugal, Conimbriga, II-III, pp. 1166.

HÜBNER, A., 1869-1892: Corpus Inscriptionum Latinarum, Berlim, vol. II.

KonRaD, C. F., 1985: A new chronology of the Sertorian war, Athenaeum, 83 (1), pp. 157-187.

Lo CAscio, E., 1982: Spesa militare, spesa dello stato e volume delle emissioni nella tarda Repubblica, AIIN, 29, pp. 75-97.

Machado, A. S., s/d: As origens da cidade do Porto. O problema de Portucale, $2^{\mathrm{a}}$ ed., Porto.

Mantas, V. G., 1990a: A rede viária do convento escalabitano, Actas del Simposio sobre la Red Viaria en la Hispania Romana, Tarazona, pp. 219-239.

Mantas, V. G., 1990b: As cidades marítimas da Lusitânia», in Les Villes de Lusitanie Romaine. Hiérarchies et Territoires (Talence, 1988), Paris, pp. 149-205.

MARTín VALLS, R., 1966: La circulación monetaria ibérica, BSAA, XXXII, pp. 207-366.

MATEU y LloPIs, F., 1949: Los tesoros monetarios de la época sertoriana, apêndice a Schulten, A., Sertorio, Barcelona.

Mattingly, H. B., 1977: Coinage and the Roman state, $N C, 17$, pp. 199-215.

NunEs, J. C. et alii, 1989: O acampamento militar romano da Lomba do Canho (Arganil): ponto da situação, Actas do I Colóquio Arqueológico de Viseu, Viseu, pp. 403-424.

PIRES, C., 1898: Moedas romanas achadas na Idanha, AP, IV, 1898, pp. 79-80.

RAdDATZ, K., 1969: Die Schatzfunde der Iberischen Halbinsel vom Ende des dritten bis zur Mitte des ersten Jahrhunderts vor Chr. Geb. Untersuchungen zur hispanischen Toreutik, Madrider Forschungen, Band 5, Berlin.

Ramires, M., 1953: Achados numismáticos, Nummus, I (4), pp. 272-273.

Roldán Hervás, J. M., 1993: Los hispanos en el ejército romano de época republicana, Salamanca.

RRC = CRAWFORD 1974.

RRCH = CRAWFORD 1969b.

Ruivo, J. S., 1995: Circulação monetária na Estremadura portuguesa até aos inícios do século III, Dissertação de Mestrado em Arqueologia, Porto (policopiada).

SÁnchez de ArZA, V., 1984: Las monedas del tesoro de Arrabalde. La Asturias Cismontana, Numisma, 186-191, pp. 51-64. 
Schubart, H. et alii, 1969: A fortificação eneolítica da Columbeira-Bombarral, $A P, 3^{\text {a }}$ s., 3, pp. 12-36.

Schulten, A., 1926: Sertorius, Leipzig.

SPANN, Ph. O., 1981: Lagobriga expugned: Renaissance forgeries and the Sertorian war, TAPA, 111, pp. 229-235.

Tovar, A., 1976: Iberische Landeskunde. Die Völker und die Städte des alten Hispanien. Band 2. Lusitanien, Baden-Baden.

Ulbert, G., 1984: Cáceres el Viejo. Ein spätrepublikanisches Legionslager in Spanisch-Extremadura, Madrider Beiträge-Band 11, Mainz am Rhein.

VAsConcellos, J. L., 1900: Antiguidades romanas de Lisboa, $A P, \mathrm{~V}$, pp. 282-287.

VASCONCELlos, J. L., 1909: Achados de moedas romanas da Republica, $A P$, XIV, pp. 58-59.

Vasconcellos, J. L., 1917a: Coisas velhas, AP, XXII, pp. 107-169.

Vasconcellos, J. L., 1917b: Pela Beira, AP, XXII, pp. 293-344.

VASCONCELlos, J. L., 1920: Estudos sobre a épocha do ferro em Portugal, AP, XXIV, pp. 99-100 e 193-197.

VASCONCELlos, J. L., 1938: Notícias do Juncal (Estremadura). (Coisas velhas, 139), AP, XXX, pp. 205-209.
VidAl BARDÁN, J. M., 1984: Tesorillo de denarios romano-republicanos de Nerpio (Albacete), $\mathrm{Nu}$ misma, 186-191, pp. 41-50.

Viegas, J. R. e Parreira, R., 1984: Der Schatzfund von Santana da Carnota (Alenquer/Portugal), $M M, 25$, pp. 79-91.

VILARET I MONFORT, J., 1976: Una troballa numismàtica de l' època sertoriana a l' Empordà, ActNum VI, pp. 47-60.

Villaronga, L., 1971-1972: Tesorillo de Albacete del año 1906, Ampurias, 33-34, pp. 305-320.

Villaronga, L., 1993: Tresors monetaris de la Península Ibèrica anteriors a August: repertori $i$ anàlisi, Barcelona.

Villaronga, L., 1994: Corpus Nummum Hispaniae ante Augusti Aetatem, Madrid.

VILLARONGA, L., 1995: La masa monetaria acuñada en la Península Ibérica antes de Augusto, I Encuentro Peninsular de Numismatica Antigua (Madrid, 7-10 Novembro 1994), Anejos de AEspA XIV, Madrid, pp. 7-14.

Vives y EsCUDERO, A., 1924-1926: La moneda hispánica, Madrid.

ZeHNACKeR, H., 1983: Le solde de l'armée romaine de Polybe à Domitien, AIIN, 30, pp. 95-121. 